\section{Thrombocytopenia with quetiapine: two case reports, one with positive rechallenge}

Rev Bras Psiquiatr 2015;37:351

doi:10.1590/1516-4446-2015-1766

Antipsychotic-induced thrombocytopenia is generally rare, but seems to occur more frequently with quetiapine. Accordingly, the relative risk of thrombocytopenia can be described as very rare with loxapine and clozapine $(<0.01 \%)$, uncommon with risperidone $(\geqslant 0.1 \%,<1 \%)$, but very common with quetiapine $(\geqslant 10 \%)$. However, very few cases are reported in the literature, ${ }^{1-4}$ with one published case of idiopathic thrombocytopenic purpura, ${ }^{1}$ and it remains unclear whether rechallenge may be considered.

Patient no. 1 was a 78-year-old male hospitalized for depressive syndrome and treated with mirtazapine $45 \mathrm{mg} /$ day, valpromide $1,000 \mathrm{mg} /$ day, and oxazepam $30 \mathrm{mg} /$ day. Quetiapine was added at $50 \mathrm{mg} / \mathrm{day}$, while mirtazapine was reduced to $30 \mathrm{mg} /$ day. Laboratory tests carried out the following day and 5 days after the start of treatment with quetiapine revealed platelet counts of $100,000 / \mathrm{mm}^{3}$ and $56,000 / \mathrm{mm}^{3}$ respectively. Two further measurements were obtained, 8 days and 28 days after discontinuing treatment with quetiapine, showing higher platelet levels of $85,000 / \mathrm{mm}^{3}$ and $120,000 / \mathrm{mm}^{3}$ respectively.

Patient no. 2 was a 72-year-old female hospitalized for personality disorders with hallucinations and treated with aripiprazole $15 \mathrm{mg} /$ day, clonazepam $0.6 \mathrm{mg} / \mathrm{day}$, valproic acid $1,500 \mathrm{mg} /$ day, furosemide $40 \mathrm{mg} /$ day, lisinopril $20 \mathrm{mg} / \mathrm{day}$, nebivolol $5 \mathrm{mg} / \mathrm{day}$, and amlodipine $10 \mathrm{mg} /$ day. During her hospitalization, aripiprazole was stopped and quetiapine $50 \mathrm{mg} /$ day was introduced. Tests performed 3 months after initiating treatment with quetiapine were notable for a platelet count of $107,000 / \mathrm{mm}^{3}$. Six days later, a second test was carried out, and the platelet count was down to $95,000 / \mathrm{mm}^{3}$. Treatment with quetiapine was suspended for 3 days, following which the platelet count went back up to $120,000 / \mathrm{mm}^{3}$. The psychiatrist reintroduced quetiapine and scheduled a control platelet test 5 days later, which showed a decrease to $84,000 / \mathrm{mm}^{3}$. In view of this positive rechallenge, quetiapine was discontinued definitively. Fifteen days after quetiapine discontinuation, the platelet count was $123,000 / \mathrm{mm}^{3}$.

In both situations, no other clinical or iatrogenic parameter seemed to account for the onset of thrombocytopenia. To our knowledge, the second patient described herein is the first case of quetiapine-induced thrombocytopenia with positive rechallenge to be in the literature.

Alexandre Lalli, ${ }^{1}$ Bruno Michel, ${ }^{2}$ Sébastien Georget, ${ }^{1}$ Catherine Bouillot, ${ }^{3}$ Anne Mangin, ${ }^{1}$ Hervé Javelot ${ }^{4}$ ${ }^{1}$ Service Pharmacie, Centre Psychothérapique de Nancy - Laxou (CPN Laxou), Laxou, France. ${ }^{2}$ Service Pharmacie, Centres
Hospitaliers et Universitaires, Strasbourg, France. ${ }^{3}$ Service de soins Archambault, CPN Laxou, Laxou, France. ${ }^{4}$ Service Pharmacie, Etablissement Public de Santé Alsace Nord, Brumath, France.

Submitted Jun 24 2015, accepted Jul 112015.

\section{Disclosure}

The authors report no conflicts of interest.

\section{References}

1 Huynh M, Chee K, Lau DH. Thrombotic thrombocytopenic purpura associated with quetiapine. Ann Pharmacother. 2005;39:1346-8.

2 Shankar BR. Quetiapine-induced leucopenia and thrombocytopenia. Psychosomatics. 2007;48:530-1.

3 Perrella C, Carrus D, Costa E, Schifano F. Quetiapine for the treatment of borderline personality disorder; an open-label study. Prog Neuropsychopharmacol Biol Psychiatry. 2007;31:158-63.

4 Handoo I, Perales M, Klaus N, Khan AY. Thrombocytopenia secondary to the use of quetiapine. J Child Adolesc Psychopharmacol. 2010;20:453-5.

\section{NBOMe: a new dangerous drug similar to LSD}

Rev Bras Psiquiatr. 2015;37:351-352

doi:10.1590/1516-4446-2015-1774

A 26-year-old Brazilian woman with a history of club drug use, in addition to cannabis and alcohol use, was referred to a clinic for substance abuse treatment after being found unconscious by security guards at a street party. Upon admission, the patient reported that she started using psychoactive substances when she was 16 years old. At that occasion, she ran away from home and started living with a friend who was a synthetic drug dealer. Motivated by the availability of drugs at a low price, and being in close contact with drug users, she started to increasingly use drugs such as 3,4-methylenedioxymethamphetamine (MDMA). Increased consumption led to increased tolerance, and as a result she started to look for substances with more powerful and longer-lasting effects. Eight months before admission, she started using NBOMe (25I-NBOMe) weekly at electronic music parties, having as many as four blotters per week. While intoxicated, the patient reported engaging in moral and sexual exposure, including being nude and masturbating in public and having unprotected sex with several different partners. After these events, she would not remember anything about the actions, locations or individuals with whom she had been. As she started treatment, she was tested for HIV and had a positive result. A diagnosis of other hallucinogen use disorder - NBOMe (304.50 - F16.20 severe) and conduct disorder (312.82 - F16.20 moderate) was established according to DSM-5 and ICD-11.

There is a growing international concern over the manufacturing and distribution of synthetic analogs of controlled substances as an attempt to circumvent drug 
laws and evade interdiction. In fact, the consumption of these substances has become a public health problem in many parts of the world. Controlled substance analogs include a large number of substituted phenethylamines; of these, the NBOMe series, a generic denomination for phenethylamines, has been attracting attention from medical and legal authorities due to the high number of cases of intoxication, followed or not by death - including in Brazil. ${ }^{1}$

This growing class of potent stimulant and hallucinogenic synthetic substances has effects similar to those of LSD and can severely affect the central nervous system. ${ }^{2}$ Recreational users of NBOMe refer hallucinogenic and dissociative effects and feelings of euphoria, fear, and paranoia. Effects range from mild to severe changes in cognition, mood and affect, with powerful sensory/somatic effects and mystical experiences. ${ }^{3}$

According to the United Nations Office on Drugs and Crime ${ }^{4}$ substances such as the $2 \mathrm{C}$ series (e.g., 2C-I) and NBOMe compounds are present in $17 \%$ of the world market of new psychoactive substances. NBOMe drugs have been sold as an alternative to LSD, with the price of a blotter ranging from $\mathrm{R} \$ 30$ to $\mathrm{R} \$ 40 .{ }^{4}$

Data on the prevalence of NBOMe use is available from only two subpopulation surveys of individuals attending nightclubs in the United States and England. In the first study, 582 of $22,289(2.6 \%)$ respondents of the 2013 Global Drug Survey reported having used an NBOMe, the most common type being 25I-NBOMe (442 of the respondents, $2.0 \%$ of the whole cohort, and $75.9 \%$ of those who had used an NBOMe). ${ }^{2}$ The second study surveyed 397 clubbers in London in 2013: $11.8 \%$ of the interviewees had heard of NBOMe drugs (compared with $96.0 \%$ for mephedrone), and $4.8 \%$ had used an NBOMe (compared with $76.6 \%$ for mephedrone). ${ }^{2}$

To the best of our knowledge, only one Brazilian study has so far been published on NBOMes. ${ }^{5}$ In that study, 77 blotters seized on the streets were analyzed; $66.7 \%$ of the samples contained one or more types of NBOMes, confirming the growing presence of these novel substances in the market. According to the author, users are often misled to believe that they are taking LSD, when in fact they are taking new, little known drugs like NBOMes or other substituted phenethylamines. ${ }^{5}$ The scarcity of research on the topic and the fact that intoxication reactions associated with these drugs are still unknown provide further grounds for concern in clinical practice.

Lysa Remy, ${ }^{1}$ Nino Marchi, ${ }^{1}$ Juliana Scherer, ${ }^{1}$ Tais R. Fiorentin, ${ }^{1,2}$ Renata Limberger, ${ }^{1,2}$ Flavio Pechansky, ${ }^{1}$ Felix Kessler ${ }^{1}$

${ }^{1}$ Center for Drug and Alcohol Research, Hospital de Clínicas de Porto Alegre, Universidade Federal do Rio Grande do Sul (UFRGS), Porto Alegre, RS, Brazil. ${ }^{2}$ Graduate Program in Pharmaceutical Sciences, School of Pharmacy, UFRGS, Porto Alegre, RS, Brazil

Submitted Jul 10 2015, accepted Aug 042015.

\section{Acknowledgements}

This study was supported by Fundo de Incentivo a Pesquisa e Eventos - Hospital de Clínicas de Porto Alegre (FIPE-HCPA; grant GPPG-HCPA 07-391).

\section{Disclosure}

The authors report no conflicts of interest.

\section{References}

1 Pagnan R, Turollo Jr R. Estudante encontrado morto usou droga e se afogou na USP, diz laudo [Internet]. Folha de São Paulo. 2014 Oct 16 [cited Jun 30 2015]. http://www1.folha.uol.com.br/cotidiano/2014/10/ 1533238-estudante-encontrado-morto-usou-droga-e-se-afogou-na-uspdiz-laudo.shtml.

2 Wood DM, Sedefov R, Cunningham A, Dargan PI. Prevalence of use and acute toxicity associated with the use of NBOMe drugs. Clin Toxicol (Phila). 2015;53:85-92.

3 Erowid.org [Internet]. 25I-NBOMe, legal status. [cited 2015 Jun 15]. https://www.erowid.org/chemicals/2ci_nbome/2ci_nbome_law.shtml.

4 United Nations Office on Drugs and Crime (UNODC). World drug report 2014. Vienna: UNODC; 2014.

5 Coelho Neto J. Rapid detection of NBOME's and other NPS on blotter papers by direct ATR-FTIR spectrometry. Forensic Sci Int. 2015; 252:87-92. 


\section{CORRIGENDUM}

We hereby inform that there was an error in the sixth author's surname in the letter entitled "NBOMe: a new dangerous drug similar to LSD," by Lysa Remy et al., published in this journal in volume 37, issue 4, pages 351-352: "Flavio Pechanky" should read "Flavio Pechansky." This is how the letter should be cited: Remy L, Marchi N, Scherer J, Fiorentin TR, Limberger R, Pechansky F, Kessler F. Rev Bras Psiquiatr. 2015;37:351-2. 